\title{
Description of measles D4-Hamburg outbreak in Hamburg, Germany, December 2008 to June 2009, which disproportionally affected a local Roma community
}

G Hegasy (guido.hegasy@hu.hamburg.de) ${ }^{1}, K_{\text {Kätzner }}^{2}$, M Helle $^{3}$, A Mankertz $^{4}$, S Baumgarte $^{5}$, A Wille ${ }^{6}$, G Fell $^{1}$

1. Centre for Infectious Disease Epidemiology, Institute for Hygiene and Environment, Hamburg, Germany

2. Public Health Department of Hamburg-Mitte, Hamburg, Germany

3. Public Health Department of Hamburg-Harburg, Hamburg, Germany

4. National Reference Centre Measles, Mumps, Rubella, Robert Koch-Institute, Berlin, Germany

5. Department of Microbiological Consumer Protection, Institute for Hygiene and Environment, Hamburg, Germany

6. Department of Medical Microbiology, Institute for Hygiene and Environment, Hamburg, Germany

Hegasy G, Kätzner K, Helle M, Mankertz A, Baumgarte S, Wille A, Fell G. Description of measles D4-Hamburg outbreak in Hamburg, Germany, December 2008 to June 2009, which disproportionally affected a local Roma community. Euro Surveill. 2012;17(24):pii=20194. Available online: http://www.eurosurveillance.org/

ViewArticle.aspx?Articleld $=20194$

Article submitted on 27 October 2011 / published on 14 June 2012

From December 2008 to June 2009 a measles outbreak occurred in the Federal State of Hamburg, Germany. The outbreak affected 216 persons and was caused by a new measles strain termed D4-Hamburg which led to consecutive outbreaks between 2009 and 2011 in at least 12 European countries. Here, we describe epidemiological characteristics of the outbreak and evaluate the control measures taken in Hamburg. In one of the seven boroughs of Hamburg a local Roma community comprised more than $50 \%$ of the notified cases. We compared in a stratified analysis the age distribution of these cases with cases of fellow citizens who did not belong to the Roma community. The age group of infants (0-11 months) comprised $33 \%$ among the non-Roma measles cases, while in the Roma community only $4 \%$ belonged to this stratum. In the stratum of 5-17 year-olds only $8 \%$ were affected among the non-Roma cases, whereas in the Roma community $50 \%$ belonged to this age group. We discuss the influencing factors that might have led to this difference in age distribution between the two groups.

\section{Background}

In December 2008 a measles outbreak started in the city of Hamburg, reached its peak during February and March 2009 and ended in June 2009 [1]. As demonstrated later by molecular typing, this outbreak was the origin of European-wide spread of a measles strain closely related to D4-Enfield, but later classified as a separate strain on the basis of sequence analysis. Consequently this strain was named D4 Hamburg. The spread of this D4-Hamburg virus continued in Europe in the following three years and led to consecutive outbreaks in Bulgaria, Poland, Ireland, Northern Ireland, Austria, Greece, Romania, Turkey, Macedonia, Serbia, Switzerland and Belgium with over 25,000 persons infected [2].
The following surveillance data on the D4-Hamburg outbreak concerning age, vaccination status and hospitalisation rate of cases have been published earlier $[1,2]$ and are only briefly summarised here: The age range of cases was 1 day to 54 years; the mean age was 14.6 years and the median age was 13.5 years. A vaccination card was available for 196 of 216 cases (91\%). Of these, 157 cases had no record of immunisation with measles-containing vaccine (MCV), including 28 cases below the recommended vaccination age of 11 months. Of 39 cases with a record of MCV immunisation, one dose was documented for 33 cases, two doses for three cases, and for three cases the record was ambiguous. Of the 33 cases with one documented dose, 26 were contacts who had received a combined measles-mumps-rubella vaccine (MMR) as post-exposure prophylaxis, but still developed the disease. No case fulfilled the criteria for application of passive protection using antiserum according to guidelines of the German Standing Committee on Vaccination (Ständige Impfkommission, STIKO) [3]. The hospitalisation rate was $40 \%$, with pneumonia and otitis media as the most frequent complications. No fatality was reported in this outbreak.

Measles virus infection has been a notifiable disease in Germany since 2001 according to the Communicable Disease Law Reform Act (Infektionsschutzgesetz, IfSG). Vaccination guidelines are provided by the STIKO, which is affiliated to the Robert Koch Institute (RKI) representing the federal institution for disease prevention and control in Germany. According to STIKO guidelines, a first dose of MCV should be given at the age of 11 to 14 months and a second dose at the age of 15 to 23 months, preferably using combined MMR vaccine [3]. For individuals missed in the regular schedule, catch-up vaccination is recommended. Since 2010, 
the STIKO has additionally recommended a single dose of MCV to be given to any person born after 1970 who has not received two doses of MCV or does not have a medical record of a subsided measles infection [4]. This decision to extend MCV immunisation to adults was taken as a result of continuing measles outbreaks in Germany, including the outbreak described here [5].

To meet the WHO European Region measles elimination target by 2015 , a vaccination coverage of $95 \%$ for two doses of MCV is necessary [6]. According to assessment at school entry, adequate vaccination status has increased in Germany over the last 10 years, but coverage is still below this threshold (Germany $90.2 \%$, Hamburg 90.5\%) [7]. Furthermore, underserved minorities have repeatedly been involved in large outbreaks in Germany $[8,9]$. Here, we describe the measles outbreak in the Federal State of Hamburg in 2008-09, which disproportionally affected a local Roma community.

\section{Methods}

For the D4-Hamburg outbreak description, data from the electronical surveillance system were re-evaluated according to IfSG using SurvNet software of RKI. These notification data include case information on age, sex, onset and duration of disease, clinical symptoms, laboratory confirmation, epidemiological links between cases and vaccination status if available. In addition, semi-structured records on contact tracing and outbreak containment measures of the seven public health departments of Hamburg were evaluated.

Cases were defined as persons with a) a generalised maculopapular rash for more than three days AND fever AND at least one of the following symptoms: cough, coryza, conjunctivitis or Koplik spots, OR b) a generalised maculopapular rash for more than three days AND/OR fever, AND laboratory diagnosis of measles infection. Persons with laboratory diagnosis of a measles vaccine strain were excluded.

Measles virus RNA in nasopharyngeal swabs or oral fluid was detected by real-time RT-PCR performed at the municipal Institute for Hygiene and Environment as described earlier [10]. Genotyping was performed at the National Reference Centre (NRC) for Measles, Mumps, and Rubella as described earlier [11].

Analysis of the cases' areas of residence by postcode and cartography was performed employing the Geographical Information System software ESRI ArcGIS.

\section{Outbreak description}

Epidemic curve and geographical distribution The outbreak started in 2008 with a case in week 49 and a second case in week 52. It continued in 2009 from week 2 to week 25 with 214 cases (Figure 1). The case in week 52 of 2008 was initially termed as the index case for Hamburg, although the patient falling ill
FIGURE 1

Epidemic curve of measles D4-Hamburg outbreak, Hamburg, 1 December 2008-17 June 2009 ( $\mathrm{n}=216)$

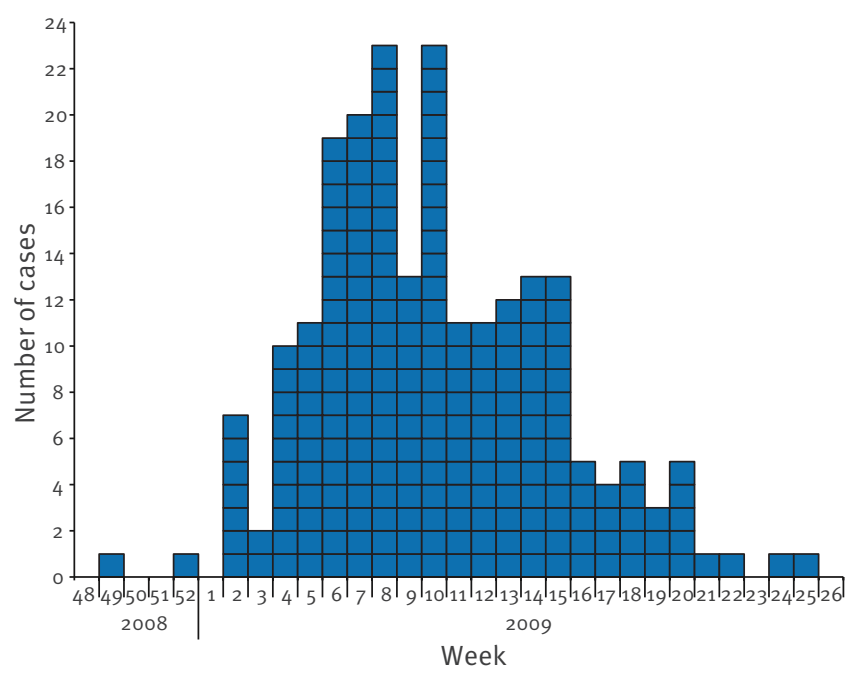

Cases were assigned to the corresponding week according to appearance of first measles symptoms.

\section{FIGURE 2}

Outbreak location in the Federal State of Hamburg, Germany, bordering Lower Saxony and SchleswigHolstein, 1 December 2008-17 June 2009 ( $n=216)$

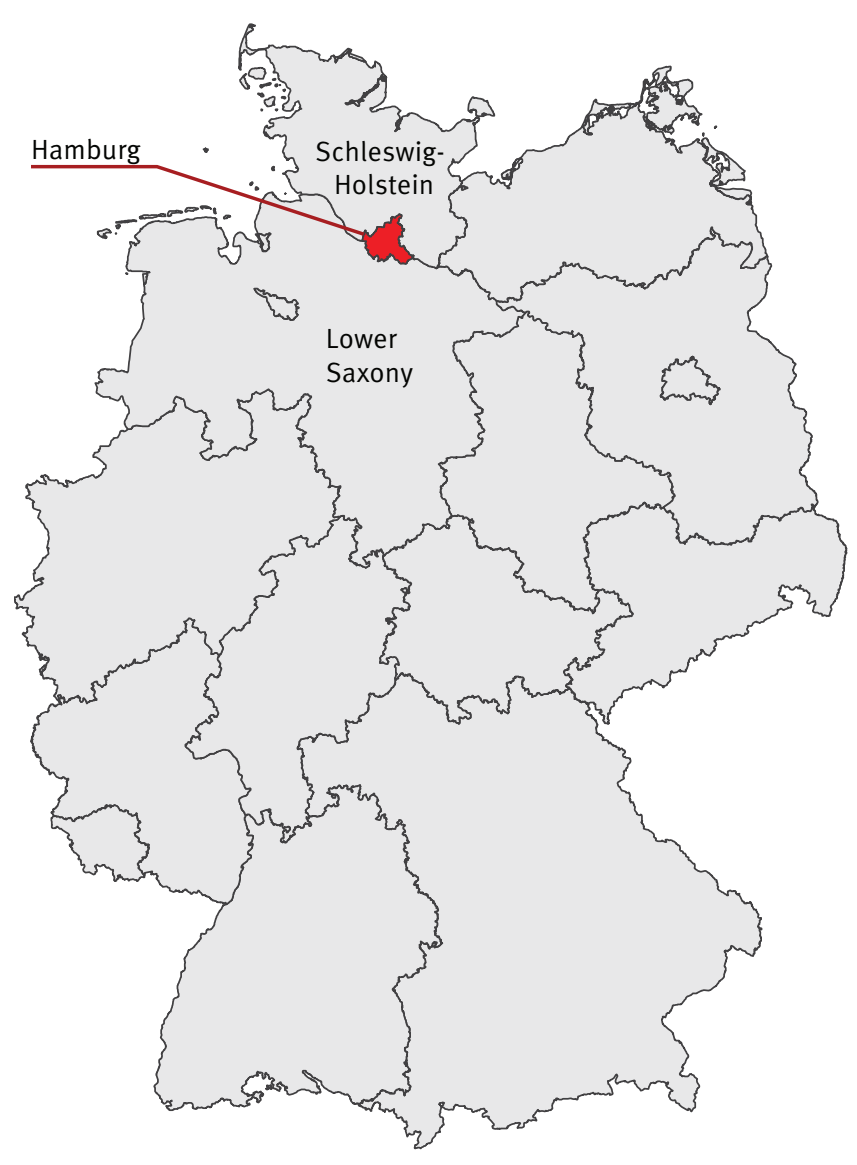


in week 49 of 2008 was retrospectively counted in as belonging to the outbreak as well. The outbreak lasted for 29 weeks with highest case numbers between week 6 and week 10 of 2009 (Figure 1).

Between week 3 and week 18 of 2009 the outbreak expanded to Lower Saxony, a bordering federal state south of Hamburg (Figure 2). Here, 53 cases were notified. Within the city limits of Hamburg the outbreak was mainly localised in the boroughs south of the river Elbe with a focus on the boroughs of Hamburg-Mitte and Harburg (Figure 3). To analyse the spatial distribution of the outbreak in more detail, postcodes of the case's place of residence were mapped using geoinformation software at the Centre for Infectious Disease Epidemiology. As demonstrated by this approach, eight of 21 postcode areas were affected in this borough. The highest incidences were restricted to the two postcode areas in the district of Wilhelmsburg (Figure 4).

\section{Clinical and laboratory-confirmed cases}

For 207 of the 216 cases the diagnosis was based on the clinical presentation and 190 of the 216 cases were linked to another case epidemiologically. For 149 of the 216 cases a laboratory confirmation was notified representing $69 \%$. For 100 of them laboratory diagnosis was based on PCR, of which 78 were confirmed by PCR alone, 20 by PCR in conjunction with IgM detection, and one each by PCR in combination with rising IgG titre or virus isolation. A further 44 of the 149 laboratory-confirmed diagnoses were based on IgM detection alone, while four cases were based solely on rising IgG titre. One case was confirmed by virus isolation in conjunction with IgM detection.

In addition to patients who received laboratory confirmation of measles infection by their family doctor, physicians of the public health departments offered immediate laboratory diagnostics during contact tracing to potentially infected individuals. To this end nasopharyngeal swabs or oral fluid were taken and analysed for measles virus RNA by real-time RT PCR. Laboratory analyses were offered free of charge to the public health departments of Hamburg by the municipal Institute for Hygiene and Environment. Of 174 persons from whom nasopharyngeal swabs or oral fluid were taken during contact tracing, 100 were found positive. This represents $67 \%$ of all laboratory-confirmed cases of the outbreak. For sequencing and genetic strain analysis, 23 swabs were sent to the NRC. Twelve of them were identified as the virus strain later termed D4-Hamburg [2]. Ten samples that were found positive in diagnostic PCR could not be sequenced successfully. For one sample sequencing revealed an infection with the vaccine virus, and consequently this patient was not counted as a case.

\section{Index case}

On 27 and 28 December 2008, a patient in their 20 S presented to the outpatient department (OPD) of a
FIGURE 3

Measles cases in the seven boroughs of Hamburg, 1 December 2008-17 June $2009(n=216)$

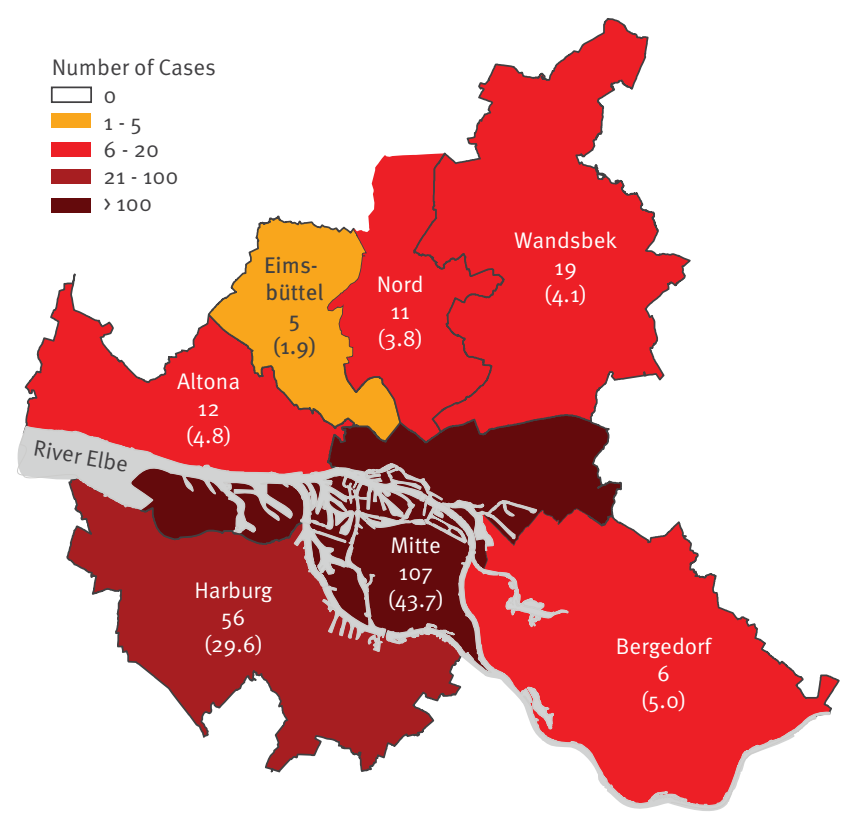

Incidence per 100,000 is given in parentheses.

\section{FIGURE 4}

Measles cases in the borough of Hamburg-Mitte by postcode areas of residence, 1 December 2008-25 May $2009(n=107)$

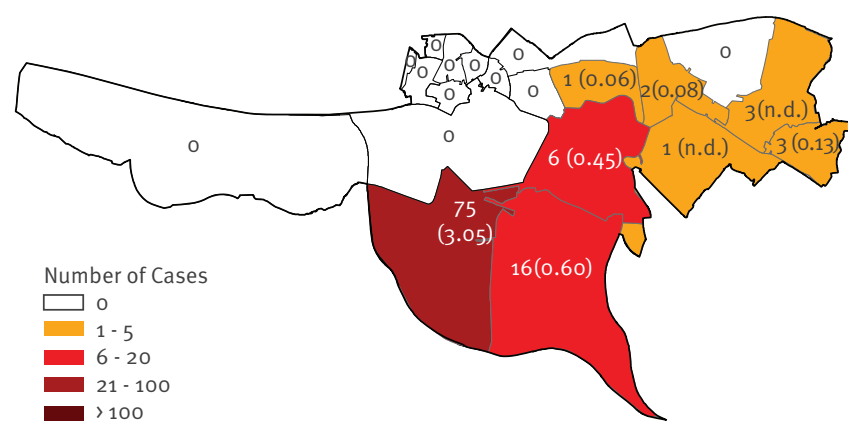

Incidence per 100,000 is given in parentheses. For two postcode areas extending outside the borough borders of Hamburg-Mitte, the incidence was not determined (n.d.).

hospital in Hamburg. The patient had suffered from a sore throat since 24 December 2008 and had developed a rash after taking acetylsalicylic acid. Under the assumption of streptococcal pharyngitis and drug eruption ambulatory treatment with amoxicillin, paracetamol and an anti-histamine was given. Because the patient's condition deteriorated, they presented on 29 December 2008 to the OPD of a second hospital where infection with measles virus was suspected and the patient was hospitalised. As any case of 
clinically suspected measles has to be notified according to the IfSG, the responsible public health department received a report on this case on 31 December 2008. Laboratory diagnosis later confirmed the infection by demonstrating positive IgM titre against measles virus and increasing Ig $G$ titres.

\section{First and following generations of cases}

The OPD visited first by the index patient was highly frequented between Christmas and New Year. The waiting area was overcrowded and patients had to wait for several hours. Potentially infectious patients were not separated. Between 8 and 11 January 2009, five persons that had been present in this OPD on 27 or 28 December 2008 fell ill with measles. These comprised two patients present in the waiting area for accident and emergency consultation, four persons accompanying patients to the OPD for medical advice in internal medicine or accident and emergency, and one hospital staff. All five cases were notified by their physicians according to the IfSG. Further spread from these five cases to household contacts was traced by the public health departments. In the entire outbreak, one or more, transmission chains were identified at each of the affected publicly accessible sites such as kindergartens, primary and secondary schools, shopping centres, and waiting areas of medical practices. Exact numbers cannot be given because not all records on transmission sites were accessible for retrospective evaluation.

\section{Spread in a Roma community}

On 26 January 2009, the public health department of Hamburg-Mitte received a report on a measles case in a woman in her 20 s who was in her 16th week of pregnancy when she was diagnosed with measles on 16 January 2009. As part of the contact tracing activities, a home visit was paid to this patient. She declared unquestioned that she belonged to a settled Roma community that traditionally lives in this borough of Hamburg. She further stated that all contact persons named by her also belonged to that community. Consequently, she was regarded as the index case for the Roma community. In the following nine weeks, 60 persons who indicated that they belonged to the same community fell ill with measles. Of those, 56 cases lived in Hamburg-Mitte which represents $52 \%$ of the 107 cases reported in this borough. The last case of the community fell ill on 19 March 2009. Additionally, in Lower Saxony seven cases stated that they belonged to the ethnic group of Roma.

On subsequent home visits paid to the community, two more cases were identified who had occurred earlier than the case regarded initially as the Roma community index: On 2 December 2008, an adolescent from the community was diagnosed with measles. The patient had been visited by relatives from London in the month of November 2008. This case was notified, but notification reached the responsible public health department with a delay of several weeks. Although no link could be found to the patient who later presented to the OPD, this adolescent was most likely the true index case of the measles D4-Hamburg outbreak. On 17 December 2008 the patient's older sibling fell ill with measles. No notification of this case was received although the patient had been seen by a physician. The older sibling was acquainted with the pregnant woman formerly regarded as the Roma community index case, but stated no personal contact to her. Even assuming a maximal length of infectious and incubation period ( 9 and 21 days, respectively), disease onset in the older sibling occurred at least five days too early to allow a direct virus transmission from them to the pregnant woman. Thus, it is highly probable that at least one more connecting case occurred in the community that was not seen by a physician, misdiagnosed or not notified.

\section{Control measures}

In all boroughs of Hamburg control measures were taken, but actions were focused on those boroughs south of the river Elbe where most cases were reported. Visits were paid to 34 community facilities such as kindergartens, primary schools and secondary schools. A community facility was selected for a visit if a case had occurred there, if a contact of a case attended that facility, or if it was located in a district highly affected by the outbreak. On these occasions, 364 doses of MCV were given on site to children as well as teachers and staff. Another 497 children who could not produce parental consent to vaccination were advised to receive $\mathrm{MCV}$ from their family doctor. A total of 701 persons attending or working at the community facilities could not provide proof of MCV immunisation or a medical record of a subsided measles infection, and were, based on IfSG, suspended for two weeks from their last potential contact to an infectious person.

In the context of enhanced measles surveillance, the frequency of case notifications from local health departments to RKI was increased from weekly to daily. In parallel, surveillance data were evaluated and compiled by the Centre for Infectious Disease Epidemiology for briefings of the State Health Department of Hamburg and for press releases targeting either the general public or specifically local physicians.

To provide information on measles to residents of affected districts and to offer low-threshold access to vaccination, a promotional bus was borrowed from the German Organisation for the Protection of Children (Deutscher Kinderschutzbund Hamburg, DKSB) and allocated for medical advice on measles prevention. Staff included two physicians, two assistants, and at least two interpreters. Interpreters were health mediators of the programme With Migrants for Migrants (Mit Migranten für Migranten, MiMi) which is described in detail elsewhere [12]. The promotional bus was opened on six occasions for four hours at central public places in the borough of Hamburg-Mitte. On these occasions 
964 consultations were requested and 18 MMR vaccinations were given.

To specifically reach the Roma community, 10 home visits were paid by the Public Health Department of Hamburg-Mitte to Roma patients and their contacts between 19 January and 5 February 2009. Staff included a physician and at least one assistant. On these occasions, vaccination cards were controlled and MMR immunisation was offered as well as laboratory diagnostics by nasopharyngeal swabs or oral fluid. No data were recorded separately for the Roma community concerning the number of persons seen, contact persons traced or vaccinations given, but on these occasions 19 PCR-positive measles cases were identified in the community.

Age distribution of cases in Hamburg-Mitte Of 107 cases notified in the borough of Hamburg-Mitte, 56 belonged to the Roma community. We considered these surveillance data as suitable for further analysis with respect to the affected Roma and non-Roma community in Hamburg-Mitte. No significant difference in sex distribution of infected individuals was seen between both groups (non-Roma: 28 male and 23 female, Roma: 29 male and 27 female, chi-squared test, two-tailed $\mathrm{p}$ value: 0.747). As shown in Figure $5 A$ the mean age of the cases was 10.1 years for the Roma group and 11.8 years for the non Roma group, while their median age was one year for the non-Roma and nine years for the Roma group. As the difference between mean and median in the non-Roma group pointed to a non-Gaussian distribution, we wanted to study the age distribution in both groups in more detail and therefore defined five age groups for a stratified analysis. Stratification was chosen as follows according to the standard vaccination schedule as recommended by STIKO guidelines [3]: (i) infants under the age for receiving MCV ( $\leq 11$ months), (ii) age range for scheduled administration of two doses of MCV (12-23 months), (iii) age range without scheduled vaccinations (2-4 years), (iv) age range for further scheduled and catch-up vaccinations (5-17 years), (v) adults ( $\geq 18$ years). As shown in Figure $5 \mathrm{~B}$, the age distribution in the strata (i) and (iv) differed between the groups.

\section{Discussion}

For outbreak surveillance to be sufficient, $80 \%$ of clinically diagnosed measles cases should according to the World Health Organization's guidelines, be laboratoryconfirmed [6]. In the outbreak described here, 149 of 216 cases $(69 \%)$ were confirmed by laboratory analyses. Of these 100 were identified by PCR from nasopharyngeal swabs or oral fluid, representing $67 \%$ of the tests. These PCR diagnostics were offered during contact tracing and home visits by the public health departments and performed at the municipal Institute for Hygiene and Environment. In contrast to serological analyses as a standard tool for laboratory diagnosis of measles infection, taking of nasopharyngeal swabs or oral fluid for PCR is non-invasive and was easily
FIGURE 5

Age distribution of affected Roma and non-Roma in the borough of Hamburg-Mitte measles D4-Hamburg outbreak, 1 December 2008-25 May 2009 (n=216)

A

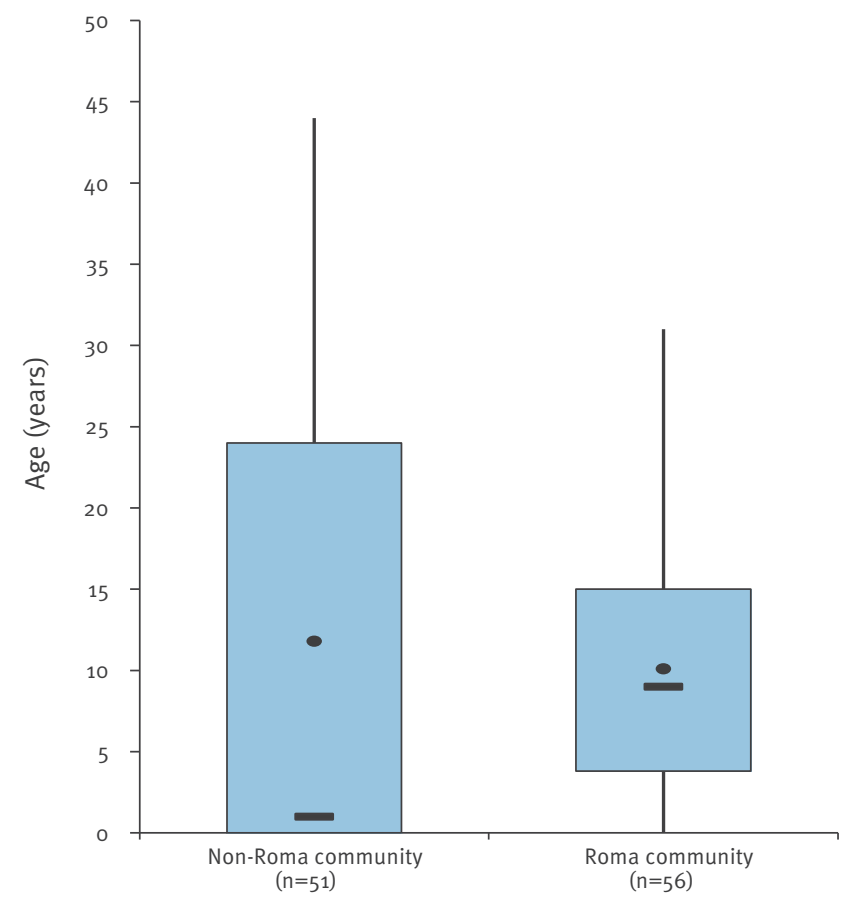

\begin{tabular}{|l|c|c|c|c|c|c|}
\hline & Mean & Median & Min & Q1 & Q3 & Max \\
\hline Non-Roma community & 11,8 & 1 & 0 & 0 & 24 & 44 \\
\hline Roma community & 10,1 & 9 & 0 & 3,8 & 15 & 31 \\
\hline
\end{tabular}

B

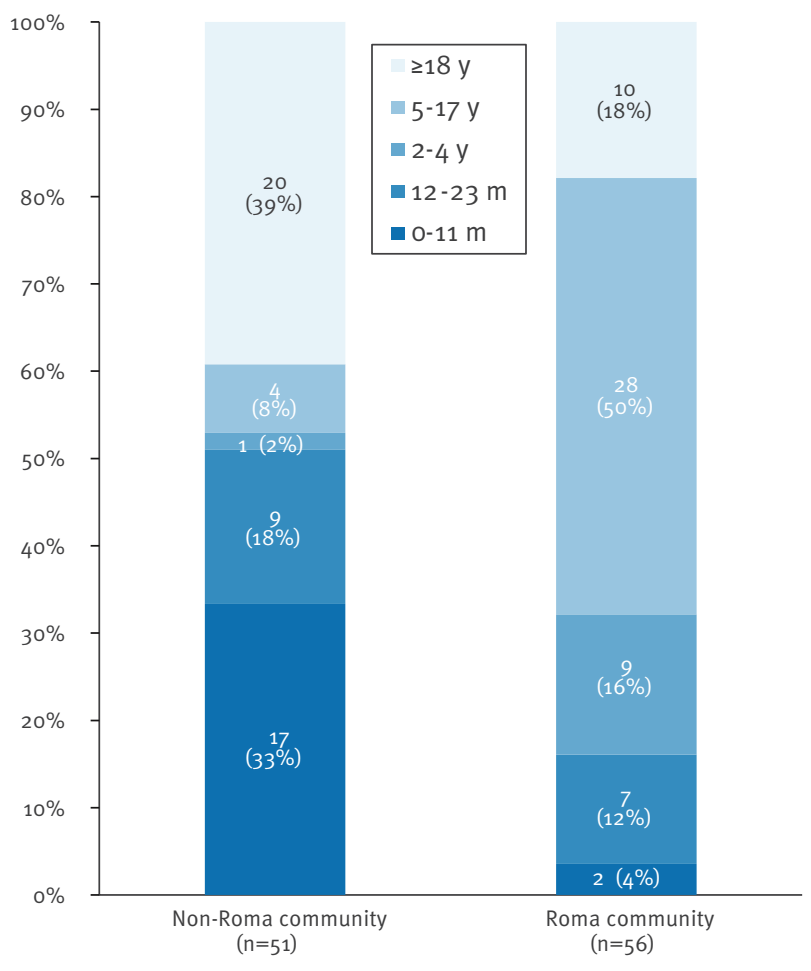

A. Boxplot showing mean, median and quartiles of disease onset age of affected Roma and non-Roma community. Figures are given in table below.

B. Stratified age analysis. Cases were assigned to groups as indicated based on age at disease onset. 
performed by medical assistants. After arrival of the material at the Institute for Hygiene and Environment, PCR results were available within four to 24 hours and thus proved to be a fast and useful tool for laboratory confirmation of suspected cases found during contact tracing. The Institute for Hygiene and Environment offered PCR analyses free of charge to the public health departments in Hamburg which do not have a budget for laboratory analyses. Furthermore, availability of nasopharyngeal or oral fluid swab material was a prerequisite for genetic comparison of the strains by the NRC and identification of the epidemiological links of the D4-Hamburg virus in Europe [2]. In summary, free-of-charge PCR analyses provided a useful tool for rapid case identification, laboratory confirmation and genetic analysis of the measles strain in the D4-Hamburg outbreak.

Healthcare facilities can play an important role in measles outbreaks $[13,14]$. This was also true for the outbreak in Hamburg, where an early focus of virus transmission was a waiting area in a hospital, and at least one further transmission site was the waiting area at a doctor's practice. Among the first generation of notified cases a member of hospital staff was identified. Later, a second case of measles in a nurse was notified. Both cases had never received a dose of MCV according to their vaccination cards. The STIKO has since 2007 recommended a single dose of MCV to be given to non-immune healthcare staff, preferably as a combined MMR vaccination [15]. Still there is no obligation to comply with this recommendation and control of adequate vaccination status of their employees is the responsibility of the healthcare facility. Suboptimal immunisation coverage of healthcare professionals in Germany has been described before [16]. The D4-Hamburg outbreak demonstrates again that prevention of disease transmission in healthcare facilities needs to be addressed.

One of the measures to contain the outbreak was a promotional bus positioned in public places on six occasions, providing information and vaccinations. Counselling was requested by 964 visitors who, according to the physicians present, were almost exclusively adults on their way to the nearby shopping centres. Only 18 persons (less than $2 \%$ of visitors) accepted on-site MMR vaccination. No data were recorded on age, sex or immunisation status, but it is likely that more visitors with inadequate measles protection did not want to receive a vaccination on this occasion. We conclude that the promotional bus as used in this outbreak was appropriate for providing information on measles to the local public, but it was not efficient in promptly raising vaccination numbers. We would therefore recommend this approach in an outbreak situation where the main intent is increasing public awareness. Furthermore, any outbreak containment measure should record all accessible data in order to allow a later evaluation of the measure's efficiency.
To specifically reach the Roma community, home visits were paid to Roma patients and their household contacts. This approach was chosen because other attempts to establish contact with cases in the community were unsuccessful. As reported by the outbreak investigation teams, initial visits to a household were received with apprehension. On subsequent visits, members of the community stated that this may have been caused by an uncertainty to which public authority the team belonged and what their actual intention was. When a team member identified themselves as a physician they were met with more trust on further visits, and contact tracing and outbreak investigations became possible. During the home visits PCR diagnostics could be offered without delay, which allowed identification of a total of 19 cases that otherwise might not have been notified. Based on information gained during the visits the likely index patient of the outbreak was identified retrospectively and the initial transmission chain in the Roma community could be partially reconstructed. Furthermore, presence of a physician allowed on-site vaccinations in the Roma community. It is a shortcoming that no data were recorded on the number of vaccinations given on these visits, but this measure might have contributed to the fact that virus transmission stopped nine weeks earlier in the Roma community than in the non Roma community of Hamburg-Mitte. In our experience, repeated home visits by a physician are an advisable approach to establish contact to this minority and to take immediate outbreak containment measures.

In a retrospective analysis we compared the age distribution of cases in the Roma community and the nonRoma community in the borough of Hamburg-Mitte. We considered the outbreak parameters as suitable for this comparison for two reasons: (i) number of cases and sex distribution were similar in both groups, (ii) both groups were citizens of the same borough, with $85 \%$ living in the same district as demonstrated by postcode analysis. No reliable figures exist on the size of this settled Roma community in Wilhelmsburg, but as an estimate, the community may comprise several hundred persons. It is a shortcoming of our analysis that no statistical reference figures are available to compare age-related incidences in the two subpopulations. Thus, our data only describe case numbers as they were recorded.

The most prominent differences occurred in the strata of 0-11 month- and 5-17 year-olds. In the non-Roma community, $33 \%$ of o-11 month-olds were infected with measles, compared with only $4 \%$ of the Roma community. This age group consists of infants too young for MCV immunisation according to STIKO guidelines. Their immune protection correlates with the level and persistence of transferred maternal antibodies and may depend on whether the mother's immunity was acquired by natural infection or by vaccination [17]. Other factors modify this passive immunity, e.g. exposure to wildtype measles virus as a natural booster or 
age of the mother during pregnancy [18]. It is tempting to speculate that early protection in the Roma community described here may have been higher because the mothers were exposed to wildtype measles infection, but this hypothesis could only be verified if data on their measles immune status were available.

Only $8 \%$ of $5^{-17}$ year-olds were affected among the non-Roma citizens, compared with $50 \%$ in the Roma community. For this age group standard and catch-up vaccinations including MCV are recommended according to STIKO guidelines. There are two mandatory checkpoints in Hamburg for control of a child's vaccination status by a physician, the first on entry to kindergarten, the second on entry to school. The first checkpoint is unlikely to reach children of a Roma community as they are usually parented by community members. At school entry the main focus is on controlling the vaccination record, and in case of undervaccination the parents are usually referred to their family doctor. This referral might be ineffective with members of a Roma community as they tend to make less use of standard healthcare and preventive services [1921]. Thus, it is conceivable that the current approach to ensure adequate immunisation status of children in Hamburg is more effective in the non-Roma than the Roma population, in which undervaccinated children and adolescents may accumulate.

In other measles outbreaks in Europe involving Roma communities, the age distribution of cases differed between Roma and non-Roma citizens [22,23], although the results of these analyses are divergent. This might be explained by differences in the subpopulation analysed (e.g. Roma or Sinti), the living conditions of the subpopulation (e.g. settled or travelling), diversity in national vaccination schemes, and different approaches to implement vaccination programmes for underserved minorities.

The group of Roma has suffered extensively from this outbreak in Hamburg and in other European countries [24]. The D4-Hamburg outbreak demonstrates again that strategies to raise measles vaccination coverage should be specifically devised to target underserved populations. Furthermore, innovative outbreak containment measures and vaccination programmes are needed. In a review of the literature concerning the interaction between Roma communities and health service providers, Hajioff and McKee came to the conclusion that published research is sparse [25]. We suggest that studies are needed to better understand the view of Roma community members towards the healthcare sector in order to be able to create vaccination programmes that are acceptable to this neglected minority.
Acknowledgments

We would like to thank Jörg Thyroff, Sabine Richtberg, Veronika Hellmund, Susanne Steinberg from the Public Health Department Hamburg-Mitte and Katharina Traudt, Joachim Kanschik from the Public Health Department Hamburg-Harburg for outbreak investigations. Furthermore we would like to thank Markus Kirchner from the NLGA, Hannover, for information on measles outbreak in Lower Saxony. Finally, we would like to thank Klaus Baumgardt from the Division for Environmental Monitoring, Hamburg, for instruction on geographic information system software. Cartography was based on standard maps from the State Office Geoinformation and Geodetic Survey, Hamburg. 


\section{References}

1. Fell G. Meldepflichtige Infektionskrankheiten in Hamburg 2009. Epidemiologischer Bericht. [Notifiable infectious diseases in Hamburg 2009. Epidemioloical report]. Hamburg: Institut für Hygiene und Umwelt; Jul 2010. Available from: http://www.hamburg.de/contentblob/2463562/data/ jahresbericht-2009-infektionsepidemiologie.pdf

2. Mankertz A, Mihneva Z, Gold H, Baumgarte S, Baillot A, Helble $\mathrm{R}$, et al. Spread of measles virus D4-Hamburg, Europe, 20082011. Emerg Infect Dis. 2011;17(8):1396-401.

3. Robert Koch Institute. Empfehlungen der Ständigen Impfkommission (STIKO) am Robert-Koch-Institut/ Stand: Juli 2011. [Recommendations of the Standing Committee on Vaccination (STIKO) at the Robert Koch Institute: July 2011]. Epidemiologisches Bulletin No 30; 1 Aug 2011. Available from: http://edoc.rki.de/documents/rki fv/rep5YpWoYJOrw/ PDF/28CKjOWgLiRzg.pdf

4. Robert Koch Institute. Empfehlungen der Ständigen Impfkommission (STIKO) am Robert-Koch-Institut/Stand: Juli 2010. [Recommendations of the Standing Committee on Vaccination (STIKO) at the Robert Koch Institute: July 2010]. Epidemiologisches Bulletin No 30; 2 Aug 2010. Available from: http://edoc.rki.de/documents/rki_fv/reLMSiAJvAFI6/ PDF/25vQaMWNX2EXrE.pdf

5. Robert Koch Institute. Änderung der Empfehlung zur Impfung gegen Masern. [Change in the recommendation for vaccination against measles ]. Epidemiologisches Bulletin No 32.16 Aug 2010. Available from: http://edoc.rki.de/documents/rki_fv/ reJeAanavg8r/PDF/2392OVQG5CQIAA.pdf

6. World Health Organization (WHO). Eliminating Measles and Rubella. Framework for the Verification Process in the WHO European Region. Copenhagen: WHO Regional Office for Europe; 2012. Available from: http://www.euro.who.int/ data/assets/pdf_file/0005/156776/E96153.PDF

7. Reiter S. Impfquoten bei den Schuleingangsuntersuchungen in Deutschland 2009. [Immunisation coverage at school entry examinations in Germany 2009]. Epidemiologisches Bulletin No 16; 26 Apr 2011. Available from: http://edoc.rki.de/ documents/rki_fv/rermiABI3LoaA/PDF/24hM4fnPQ2U.pdf

8. Bätzing-Feigenbaum J, Pruckner U, Beyer A, Sinn G, Dinter A, Mankertz A, et al. Spotlight on measles 2010: Preliminary report of an ongoing measles outbreak in a subpopulation with low vaccination coverage in Berlin, Germany, JanuaryMarch 2010. Euro Surveill. 2010;15(13):pii=19527. Available from: http://www.eurosurveillance.org/ViewArticle. aspx?Articleld=19527

9. Gold H. Zu einem Masernausbruch bei Migranten in München. [On a measles outbreak among migrants in Munich]. Epidemiologisches Bulletin No 50; 20 Dec 2011. Available from: http://edoc.rki.de/documents/rki_fv/reu8y56vT4KNk/ PDF/22deQTGmzUXbY.pdf

10. Hummel KB, Lowe L, Bellini WJ, Rota PA. Development of quantitative gene-specific real-time RT-PCR assays for the detection of measles virus in clinical specimens. J Virol Methods. 2006;132(1-2):166-73.

11. World Health Organization. New genotype of measles virus and update on global distribution of measles genotypes. Wkly Epidemiol Rec. 2005;80(40):347-51.

12. Salman R, Weyers S. Germany: MiMi Project - With Migrants for Migrants. In: Poverty and social exclusion in the WHO European Region: health systems respond. Koller T, editor. Copenhagen: WHO Regional Office for Europe; 2010. p. 52-63. Available from: http://www.euro.who.int/ data/assets/pdf file/0006/115485/E94018.pdf

13. Follin P, Dotevall L, Jertborn M, Khalid Y, Liljeqvist JA, Muntz S, et al. Effective control measures limited measles outbreak afte extensive nosocomial exposures in January-February 2008 in Gothenburg, Sweden. Euro Surveill. 2008;13(30):pii=18937. Available from: http://www.eurosurveillance.org/ViewArticle. aspx?Articleld $=18937$

14. Botelho-Nevers E, Cassir N, Minodier P, Laporte R, Gautret $\mathrm{P}$, Badiaga S, et al. Measles among healthcare workers: a potential for nosocomial outbreaks. Euro Surveill. 2011;16(2): pii=19764. Available from: http://www. eurosurveillance.org/ViewArticle.aspx?Articleld $=19764$

15. Robert Koch Institute. Empfehlungen der Ständigen Impfkommission (STIKO) am Robert-Koch-Institut/Stand: Juli 2007. [Recommendations of the Standing Committee on Vaccination (STIKO) at the Robert Koch Institute: July 2007]. Epidemiologisches Bulletin No 30; 27 Jul 2007. Available from: http://edoc.rki.de/documents/rki_fv/re3BNEVpkzVE/ PDF/27RqkoxJi3JThw.pdf

16. Voigt K, Kühne F, Twork S, Göbel A, Kugler J, Bergmann A. [Current vaccination status of health-care personnel in Brandenburg, Saxony And Saxony-Anhalt]. Gesundheitswesen. 2008;70(7):408-14. German.
17. Leuridan E, Hens N, Hutse V, leven M, Aerts M, Van Damme P. Early waning of maternal measles antibodies in era of measles elimination: longitudinal study. BMJ. 2010;340:C1626.

18. Leuridan E, Van Damme P. Passive transmission and persistence of naturally acquired or vaccine-induced maternal antibodies against measles in newborns. Vaccine. 2007 21;25(34):6296-304.

19. Muscat M. Who gets measles in Europe? J Infect Dis. 2011;204 Suppl 1:S353-365.

20. Feder GS, Vaclavik T, Streetly A. Traveller Gypsies and childhood immunization: a study in east London. Br J Gen Pract. 1993;43(372):281-4.

21. Kraigher A, Vidovic M, Kustec T, Skaza A. Vaccination coverage in hard to reach Roma children in Slovenia. Coll Antropol. 2006;30(4):789-94.

22. Curtale F, Perrelli F, Mantovani J, Ciofi degli Atti M, Filia A, Nicoletti L, et al. Description of two measles outbreaks in the Lazio Region, Italy (2006-2007). Importance of pockets of low vaccine coverage in sustaining the infection. BMC Infect Dis. 2010;10:62.

23. Pervanidou D, Horefti E, Patrinos S, Lytras T, Triantafillou E, Mentis A, et al. Spotlight on measles 2010: ongoing measles outbreak in Greece, January-July 2010. Euro Surveill. 2010;15(30):pii=19629. Available from: http://www. eurosurveillance.org/ViewArticle.aspx?Articleld=19629

24. European Centre for Disease Prevention and Control (ECDC). Measles disproportionately affects Roma. European monthly measles monitoring (EMMO). Issue 6. Stockholm: ECDC; Nov 2011 Available from: http://ecdc.europa.eu/en/publications/ Publications/1112_European_monthly_measles_monitoring Nov_2011.pdf

25. Hajioff S, McKee M. The health of the Roma people: a review of the published literature. J Epidemiol Community Health. 2000;54(11):864-9. 